\title{
Risk factors of school bullying and its relationship with psychiatric comorbidities: a literature review
}

\author{
Gellan K. Ahmed ${ }^{1,2^{*}} \mathbb{0}$, Nabil A. Metwaly ${ }^{3}$, Khaled Elbeh ${ }^{1}$, Marwa Salah Galal ${ }^{4}$ and Islam Shaaban ${ }^{3}$
}

\begin{abstract}
Background: School bullying is described as violence to other people. It is perpetrated at schools or other activities when the power of a student or a group of students is used to injure others or other groups.

Main body: The prevalence of school bullying is varied from one country to another. There are many types of bullying, such as physical, verbal, social relations, psychological, sexual, and cyber-bullying. Many risk factors could affect school bullying, especially individual, peer and parent factors. Researches found that adults who had school bullying are more vulnerable to develop future psychiatric disorders.

Conclusions: School bullying is one of the crucial problems among pupils. The wide range of the prevalence of school bullying may be due to different methodologies and the presence of many risk factors. It is recommended to have long-term researches about the student with bullying behavior. Also, prevention programs are required to increase knowledge and early detection of affected students to prevent future psychiatric disorders.
\end{abstract}

Keywords: Bullying, Risk factors, Psychiatric comorbidity

\section{Introduction}

School bullying is the most prevalent kind of youth violence that has become a significant concern for pupils and a global public health issue [1]. Bullying is defined as "a type of aggressive behavior in which someone else causes injury or discomfort intentionally and repeatedly [2].

Bully's strength is based on physical strength, age, financial position, and social and technical competencies [3].

Bullying in school is distinct from other forms of violence, as well as from simple interpersonal conflict between students in three ways [4].
1. Intention to cause harm.

2. Repetition of the harmful acts.

The power imbalance between the bully (perpetrator of bullying) and the bullied (victim). The bullying perpetrator has an advantage over the victim, such as physical strength and size, social position, authority, and popularity.

\section{Main text}

\section{Prevalence of bullying}

Despite the intrinsically hard task of estimating the prevalence of bullying due to different measures used in different studies, researchers generally agree that bullying is a widespread and significant problem in today's schools [5]

\section{Studies in Arab countries}

A Cairo-based study evaluating the prevalence of violence among elementary-aged schoolchildren found that 
public and private schools experienced different violence. For example, $76 \%$ of public school children reported experiencing physical violence, while $62 \%$ of private school children reported experiencing physical violence [6]. In 2019, another Egyptian study, done by Galal and his colleagues looked at rural schools to discover the proportion of bullies among middle and high school students. The researchers found that $9.5 \%$ of the students surveyed were bullies [7]. Another study reported prevalence rate of bullying behaviour among 280 elementary students in Sohag at Egypt was about 12.5\% [8].

Few studies have been done to determine the frequency of bullying in the Arab world. According to the Global School-based Students Health Survey, middle school students in 19 low- and middle-income countries have an average rate of 34.2 percent for peer victimization, with rates of 44.2 percent in Jordan, 33.6 percent in Lebanon, 31.9 percent in Morocco, 39.1 percent in Oman, and 20.9 percent in the United Arab Emirates [9].

\section{International prevalence of bullying}

A meta-analysis of 80 studies from various countries focused on students in grades six through eight has found that bullying involvement rates can range from 9 to $98 \%$, with the average rate being $35 \%$ [10].

Victimization rates were reported to range from 2 to $66 \%$ in China, while perpetration rates varied from 2 to $34 \%$ (Chan and Wong 2015). Another study reveals that bullying is widespread in Southeast Asian countries, as the prevalence rate was $1 \%$ to $7.7 \%$ [11].

The United Nations Educational, Scientific and Cultural Organization [12] report shows that making educational environments violence-free and creating a safe learning environment for all children is still a top priority for the world. However, according to this report, bullying and other forms of violence affect one third of young people. Still, the rates of bullying victimization differ depending on which region is in question.

\section{Bullying comes in various ways and styles [13]}

Physical bullying includes slapping, kicking, and punching.

Verbal bullying includes things such as name-calling, taunting, threatening, racial slurs, name-calling, cursing, and more.

Psychological bullyings such as harassment, intimidation, and humiliation.

Bullying in social relations Social rejection or preventing people from engaging in certain activities.

Sexual bullying Threats or sexual touching, use dirty words, or being grabby.
Cyber-bullying When someone uses texts, social networks, or hacking to ridicule or intimidate someone.

Direct and indirect bullying are the two general categories of bullying types. In the face-to-face form of bullying, there are physical attacks and verbal harassment. Indirect bullying includes social exclusion, spreading rumors, and similar passive-aggressive behaviors. Therefore, in other words, direct bullying involves aggressive tactics, such as bullying, humiliating, and ridiculing, while more subtle bullying methods are trying to hurt someone socially, get others to avoid them, and keep others in the dark about who did it [14].

Direct bullying has been observed in young children, where direct physical abuse has been substituted progressively with verbal bullying [15]. Different forms of bullying are seen as stemming from gender-based differences. Female students engage in verbal bullying more often than male students, whereas male students employ direct physical bullying [16].

In the group-related bullying process, school students are members of various social groups, and they take on multiple roles, such as bullying perpetrators, victims, and witnesses, to reinforce the hierarchy [17].

There are different roles related to both the bully and the victim, and some of these roles increase the chance that bullying will happen-these positions as [17].

a) Ringleader bullies: they are persons who are planning, over a long time, to harm the victim again and again.

b) Assistants: they are followers who aid the bully and engage in aggression against friends.

c) Reinforcers: these are persons who pay attention to the bully and smile or laugh during the act of bullying.

d) Defenders: they are persons who help the victim to feel better or to intervene to stop this act.

e) Victims: they are the target of peer attack and feel they cannot defend themselves easily from a bully.

f) Bystanders observe students: who are both bullies and victims

\section{Risk factors of school bullying (see Table 1)}

\section{Individual risk factors}

1. Gender

Since girls and boys can both be bullies and victims of bullying, research has found that boys are more likely than girls to be bullied [18]. The gen- 
Table 1 Summary of risk factors for bullying

\begin{tabular}{ll}
\hline Risk factors for bullying & \\
Individual risk factor & Gender \\
& Grade level \\
& Ethnicity \\
& Socioeconomic status \\
& Physical features and body built \\
& Externalizing behavior \\
& Self-esteem \\
& Social skills and popularity \\
& Academic achievement \\
& Disability status \\
& Peer group norms \\
& Delinquency \\
Peer group risk factors & Drug and alcohol abuse \\
& School climate \\
School risk factors & Teacher attitude \\
& Classroom characteristics \\
& School belonging \\
Parental risk factors & Parental characteristics \\
Community risk factors & Family discord \\
& Neighbourhoods \\
& Social media \\
\hline &
\end{tabular}

der disparity in bullying is more significant for direct actions of bullying such as physical assault or threats. However, this relationship is less significant for indirect bullyings such as rumor propagation or social isolation [19].

Nearly $24 \%$ of females reported being bullied, while only $18 \%$ of males reported this. A similar pattern occurred with rumors: $15 \%$ of females compared to $9 \%$ of males reported being targeted. However, males (5\%) have reported threats of harm more than females (3\%) (National Center for Educational Statistics, 2016).

2. Grade level

The rate of bullying decreases as children age, from primary to high school [20]. Bullying is most common in middle school, but research shows that it is at its highest in schools as students prepare to enter high school (i.e., between elementary and midschool and middle schools and high school)[21].

3. Ethnicity

Bullying involvement is an intercultural and ethnic phenomenon. For example, research has shown that school students who belong to an ethnic minority are more likely than an ethnic majority to be harassed [22].
4. Socioeconomic status

Higher levels of victimization have involved increased disparities between socioeconomic status within one country [23].

5. Bodybuilding and physical characteristics

Powerful men tended to be bullies, according to [19]. According to Unnever and Cornell (2003), bullies in the United States are taller and more robust than their peers. Male students detected a significant quadratic association (U-Shaped) between the bodyweight status and the harassment, while female students did not [24].

These results imply that underweight and obese boys are more likely than their average-weight peers to become bullied, reflecting the theory of conflict that a bullying victim is often different from the majority [25].

6. Externalizing behavior

Being a bully is commonly seen to be associated with externalizing behavior (e.g., aggressive, defiant, disruptive, or delinquent), whereas being a victim is associated with internalizing behavior (e.g., anxiety, depression, or poor self-esteem) [18].

7. Self-esteem

There was a widespread belief that low self-esteem leads to aggression, including bullying. Despite the fact that (weakly) negative self-related insight is linked to bullying, the chances of being a pure unvictimized bully are not greater [18]. Research suggests that narcissism, arrogance, and callous emotional traits (such as a lack of empathy and shame) are more closely linked to bullying than previously assumed [26].

8. Popularity and social skills

A "social relationship problem" has been used to describe bullying [27]. Indeed, victims, bully-victims, and some bullies have social skills deficiencies [18].

Even if many classmates do not necessarily like them personally, bullies can be seen among their peers as popular, influential, and "cool" [28]. In addition, bully members are often central and have friends in their peer networks. Like other people who engage in and affiliate with similar behaviors [29], teenagers can strengthen the coercive behavior of the other.

9. Academic achievement

The connection between bullying and academic performance is difficult. Previous studies vary whether bullies are slightly low or significantly low in school performance. The study investigated 46 
schools' exam results and found that peer bullying was associated with lower achievement, especially if teased students missed school and missed educational opportunities [30]. Three African nations included 12-16 years who were enrolled in a Trend Studies in Mathematics and Science class. According to their findings, bullying is both a significant problem in all three countries, and is a significant and common factory related to poor academic performance [31].

10. Physical disability

Students with conduct disorders are more likely to be bullied but bullying can be retaliatory in response to bullying [32].

\section{Peer group risk factors}

\section{Peer group norms}

If members of a peer group participate in bullying, the others experience it. In addition, students who were bully perpetrators were more likely to come from socially significant peer groups [33].

2. Delinquency

The influence of peers was a significant predictor of participation in harassment; Negative peer influence was linked to bullying and being victimized [18]. In addition, research shows that having a delinquent record (i.e., vandalism, membership in a gang, and bringing a weapon to school) correlates with higher levels of bullying and victimization [34].

High pro-social behavior and low social anxiety benefit academic success, because it helps students avoid getting bullied or victimized and thus succeed academically [35].

3. Alcohol/drug use Bullying and alcohol/drug abuse are known to be linked. For example, a study of adults in the United States discovered that bullying was significantly associated with lifetime alcohol and drug use. Thus, involvement in bullying is linked to both concurrent and future alcohol/drug use [36].

\section{School risk factors}

\section{School climate}

Adults play an important role in creating a positive or negative environment in schools. If the school environment is not good and unhealthy, bullying and related problems are widespread [37]. Bullying and victimization, on the other hand, are less prevalent when students are challenged and motivated to do well in school [38].

2. Teacher attitude

The role of the teacher is critical in the fight against bullying in the classroom [39]. Teachers' responses to bullying will vary depending on their individual beliefs and attitudes.

Some teachers regard bullying as a normal behavior that may aid children in developing social skills and believe it is unnecessary to intervene, because they do not sympathize with the victim [40].

Furthermore, teachers will not likely interfere with bullying when they perceive that conduct is not bullying or when there are other occurrences of hidden forms such as relational or verbal bullying or when teachers do not perceive the behavior as bullying [41].

3. Classroom characteristics

Schools are an amalgamation of many classrooms and there is an incentive for reducing bullying and victimization in healthy a classroom environment. A study identified four key characteristics that predict bullying in classrooms: (1) negative peer relationships, (2) poor teacher-student relationships, (3) a lack of self-control, and (4) poor problem-solving abilities among students [42].

4. School belonging

Those who bullied others in primary school had lower rates of school affiliation than those who had been or had not been bullied victims $[43,44]$.

\section{Parental risk factors}

\section{Parental characteristics}

Researchers have found that bullies are more likely to come from families, where there is little cohesion, little warmth, absent fathers, high power needs, and a tolerance for aggressive behavior. They may also have experienced physical abuse as well as being from low socioeconomic status families with authoritarian parents [45].

The mothers of the male victims were overprotective, controlling, restricting, coddling, overinvolved, and warm, whereas their fathers were aloof, critical, absent, indifferent, negligent, and domineering. Female victims, on the other hand, had hostile moms who denied or rejected affection, threatened and dominated them, and fathers who were careless and carefree [18]. 
2. Family discord

Being raised in a home, where the parents fought, drank, used drugs, and were physically or sexually abusive predicted bullying and bullying victimization in children $[43,44]$. A lack of parental guidance and conflict in the home are common themes among bullies [18].

\section{Community risk factors \\ Neighborhoods}

Neighborhood characteristics have a significant impact on bullying behavior [18]. For example, bullying thrives in neighborhoods that are unsafe, aggressive, and unorganized. Conversely, living in a safe, connected neighborhood was associated with lower levels of bullying and victimization [7].

\section{Societal risk factors \\ Media}

Decades of research have been conducted to determine whether exposure to violent video games, television, and film is linked to higher levels of aggression. Indeed, meta-analyses of these studies show that media violence is associated with aggressive and antisocial behavior [46].

\section{Diagnosis of bullying behavior}

A- Criteria of bullying behavior.

B- Psychometric Scales for the bullying behavior

\section{Criteria of bullying behavior}

A list of features used to identify bullying [47]: Bullying is widely accepted to be a subcategory of aggressive behavior defined by the three minimum criteria listed below:

Intent to hurt (i.e., the harm caused by bullying is deliberate, not accidental).

1. Power disparity (i.e., bullying includes a real or perceived power inequity between the bully and the victim).

2. Long-term repetition (i.e., more than once with the potential to occur multiple times).

To supplement the above-mentioned criteria, the following two additional criteria have been proposed:

1. victim distress (victim suffers mild to severe psychological, social or physical trauma).

2. incitement (bullying is motivated by perceived benefits of their aggressive behaviors).
Psychometric Scales for the bullying behavior

Scales for the bully: There are many scales used to assessed bully behavior, such as.

Bullying behavior Scale for children and adolescents [48]: It is 40 items that used to measure the frequency of self-reported perpetration in different forms of Bullying for Youth 8-18 years.

Aggression Scale [49]: It is 11 items that used to assess the frequency of self-reported perpetration of teasing, pushing, or threatening others for Youth 10-15 years.

Bullying behavior Scale [50]: It is six items that are used to assess bullying behavior at schools for Youth 8-11 years.

Modified Aggression Scale [51]: It is nine items that used to assess bullying behavior and anger for Youth 10-15 years.

\section{Scales for the victim}

Gatehouse bullying Scale [52]: It is 12 items that used to assess overt and covert victimization for Youth 10-15 years.

Retrospective Bullying Questionnaire [53]: It is 44 items that used to assess the frequency, seriousness, and duration of bully victimization in primary and secondary school; bully-related psychological trauma, suicidal ideation if bullied, and bullying in college and the workplace for young adults/Adults 18-40 years.

Perception of Teasing Scale (POTS) [54]: It is 22 items that used to measure the frequency and effect of teasing and bullying for youth 17-24 years.

\section{Scales for the bully-victim}

Olweus Bullying Questionnaire: It is 39 items that used to assess the frequency of bully perpetration and victimization for Youth 11-17 years.

School life survey [55]: It is 24 items that used to assess the frequency of physical, verbal, and relational bullying as both the perpetrator and the victim for Youth 8-12 years.

School relationships Questionnaire [56]: It is 20 items used to assess the victimization and perpetration of direct and relational bullying/ aggression for Youth 6-9 years.

Illinois Bully Scale [57]: It is 18 items that used to assess the frequency of bullying behavior, fighting, and victimization by peers for youth $8-18$ years.

\section{The effects of bullying behavior}

The consequences of bullying are extensive, not only to the individuals involved in these conflicts but for society more widely. Scientific research indicated that experiencing bullying has a short and long-term psychological and emotional impact on both victims and perpetrators [58, 
Table 2 Effects of bullying behavior

\section{Effects of bullying behavior}

\section{Effects on the bully}

Short term effects [60]

Poor school performance (missed school due to suspensions increases this risk) Increased truancy risk

Difficulty maintaining social relationships

Increased risk of substance abuse

Effects for the victim

Short term effects [61]

Social isolation

Feelings of sham

Sleep disturbance

Changes in eating habits

Low self-esteem

School avoidance

Symptoms of anxiety

Bed wetting

Higher risk of illness

Psychosomatic symptoms (stomach-aches, headaches, muscle aches, other physical complaints with no

known medical cause)

Poor school performance

Symptoms of depression

Effects on school community [60]

Student body less engaged in school activities

Lower overall performance on standardized tests

Lower graduation rate

Effects on society [60]

Disproportionate need for societal support systems such as

Extended sick leave

Unemployment

Uncollected tax revenues

Increase of health care costs
Long term effects [61]

Risk of spousal or child abuse

Risk of antisocial behaviour

Substance abuse

Less likely to be educated or employed

Long term effects [60]

Chronic depression

Increased risk of suicidal thoughts, suicide plans, and suicide attempts Anxiety disorders

Post-traumatic stress disorder

Poor general health

Self-destructive behavior, including self-harm

Substance abuse

Difficulty establishing trusting, reciprocal friendships, and relationships

Table 3 The effect of bullying on children versus adolescents

Effects of bullying behavior on children

\begin{tabular}{lll}
\hline Victim & Bully & Bully-victim \\
$\begin{array}{l}\text { Depression and Anxiety [62] } \\
\text { Suicidal ideation and behaviour [63] }\end{array}$ & Suicidal ideation and behaviour [63] & Depression and Anxiety [62] \\
$\begin{array}{l}\text { Feeling tired, Poor appetite, Stomach-ache, Sleeping difficul-- } \\
\text { ties, Headache, Back pain, Dizziness [63] }\end{array}$ & Panic disorder and Hyperactivity [64] \\
Alcohol misuse [64] and Smoking & Poor school adjustment [64] & Disturbed personality [64] \\
Panic disorder [63] & Externalising problems [64] & Poor social adjustment and isolation [64] \\
Victim [62] & Bully [62] & \\
Depression and Anxiety & Depression and Anxiety & Bully-victim [62] \\
Panic disorder & Panic disorder & Depression and Anxiety \\
Suicidality & Suicidality & Panic disorder \\
& Disturbed personality & Suicidality \\
& Violent crime and drug misuse [65] & Violent crime and drug misuse [65] \\
\hline
\end{tabular}


59]. Also, there are many effect of bullying behaviour that different if happen for childern or adolescents (see Tables 2, 3).

1. Effects on the bully

2. Effects on the victim

3. Effects on the school community

4. Effect on the society

\section{Psychiatric comorbidities with bullying}

Bullying is a distressing experience that often lasts for years, persists into adulthood, and correlates with current and future psychiatric issues [66]. If the bullying (or being bullied) does not stop or interfere with functioning at school or with friends, pupils should be assessed for potential psychiatric issues [67].

Comorbidity of these disorders [such as depression, anxiety, conduct disorder, oppositional defiant disorder, and attention deficit hyperactivity disorder (ADHD)] occurs among children involved in bullying [68]. At the same time, it is comparatively uncommon in nonbullied children. In addition, separation and generalized anxiety disorder, dysthymia, depression, and panic disorder may be found in the results of an examination of a child who has been the victim of bullying [67].

During adulthood, victim and bully-victims males are at an increased risk for anxiety and personality disorders characterized as histrionic and paranoid [69].

Bullying can begin early in life and persist into adulthood, leading to poor mental and physical health and compromised interpersonal relationships [70].

The consequences of childhood bullying and the correlates of bullying in adulthood can be examined through studies that use adult samples [71]. However, to date, few longitudinal studies have examined general population adult correlates of bullying.

A study in Finland followed bullied elementary school boys into adulthood. This study claimed that bullying could have significant social and psychological effects over time. Boys who bullied others showed that adults are much more prevalent than their unbullying counterparts in antisocial personality disorder, criminality, and convictions [72].

Bullying in childhood is also associated with an increased risk of substance abuse (alcohol, cannabis, and nicotine use disorder), depression, and anxiety in adulthood. In addition, the results indicate that having a psychiatric disorder can increase your risk of being bullied as a youth [72].

Suicide is the second highest cause of mortality among adolescents aged 15 to 29 [73]. Students who have been bullied are twice as likely to have suicidal thoughts and are 2.6 times more likely to attempt suicide than students who have not been bullied [74]. In addition, Suicidal conduct is reported by students, whether they are bullies, victims, or witnesses [73]. In 2014, About17.7\% of school-aged kids attempted suicide due to bullying behaviour, according to the Youth Risk Behavior Survey (YRBS) [75].

These negative consequences highlight the importance of further research into bullying to develop effective intervention strategies. We must first comprehend violence and bullying to prevent them. Examining the individuals involved in bullying would be a good first step toward understanding.

\section{Prevention and management}

Some of these consequences can be avoided with immediate intervention and long-term follow-up. Schools, families, and communities must work together to understand bullying and its consequences, as well as to discover solutions to reduce, and eventually eliminate, bullying in schools and communities [60]. Therefore, The United Nations Children's Fund (UNICEF) put prevention and management program to bullying behaviour (for details see Tables 4, 5).

In 2018, UNICEF showed that 70\% of Egyptian children aged 13-15 are bullied; as a result, Egypt adopted draught revisions to prohibit bullying [76]. Fortunately, in recent years, there have been several initiatives as well as individual attempts to combat bullying. Egypt started its first nationwide campaign in 2018, pushing children, parents, and caregivers to speak up against bullying and providing suggestions and guidance on how to deal with it [77]. In addition, the first legal judgement of its kind was given in Egypt in july,2020 with two defendants sentenced to 2 years in prison and fined EGP 100,000 (about $\$ 6,250)$ [78].

Anti-bullying campaign in Egypt, funded by the European Union and coordinated by the National Council for Childhood and Motherhood (NCCM), the Ministry of Education and Technical Education and The United Nations Children's Fund (UNICEF). They want to create a safe atmosphere for kids by raising awareness about bullying and how to deal with it through a child protection programme [76]. Some issues may be needed to solve to help this program to fit Egyptian culture such as need for supervisory bodies to monitor teachers and pupils behaviour, need for educational courses for parents and teachers about bullying and having cooperation between school authorities and specialized psychiatrists to treat the problem of bullying with the presence of mental illnesses. 


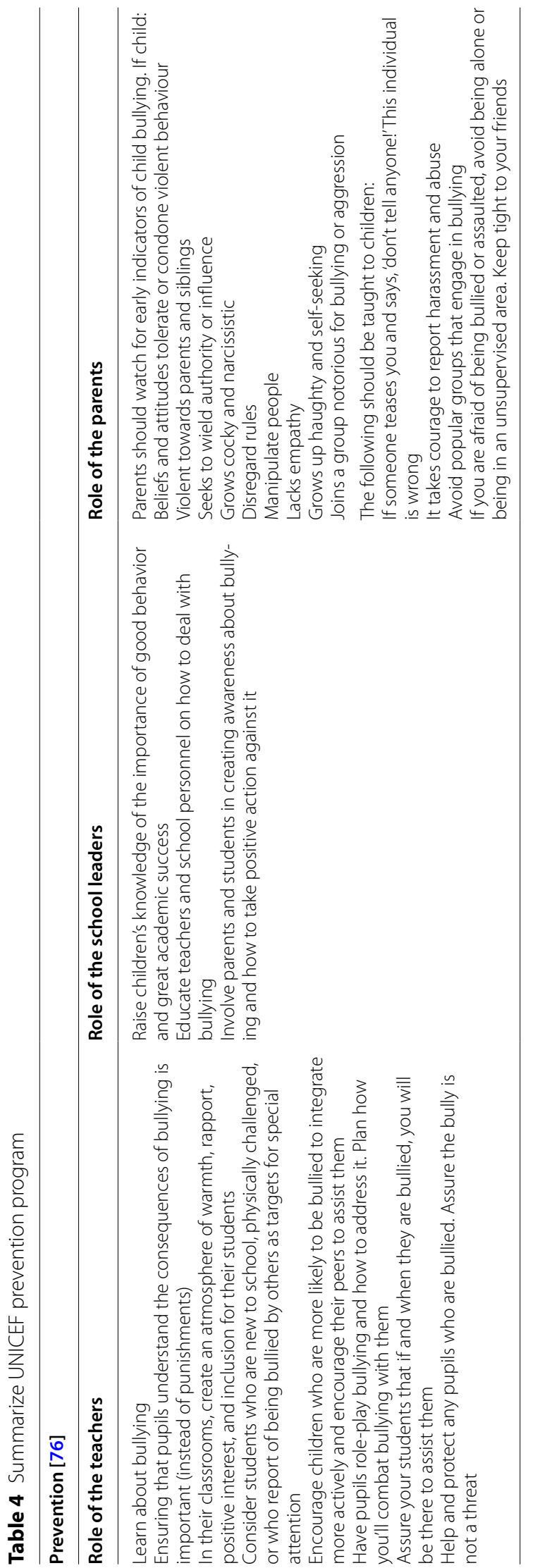


Table 5 Summarize UNICEF Intervention program

\section{Intervention [76]}

\section{If the child is a bully}

1. Role of the teachers

- Consider their interpretation of events

- Point out unsuitable or undesirable behaviour and remind them of the anti-bullying principles and classroom norms

- Understand the causes for their bullying conduct

- Show empathy and compassion by empathising with the kid being bullied

- Apply specific punishments to help them learn

- The kid should correct his errors

-Participation in events, travels, sports, artistic activities, or anything the youngster deems acceptable and fascinating

- Plan with their parents
- Explain that rules must be followed to gain classroom privileges

\section{If the child is a victim}

1. Role of the teachers

Treat the incident with seriousness - Thank the bullied for reaching you and praise their efforts

- Assure him or her that the prob-

lem is not his or her fault

- Exhibit empathy

- Assist the bullied in asserting his or her rights

- Ask the kid what they can do to feel safe

- Don't yell at them or blame them. Honesty is rewarded and encouraged

- If a child bullies another child with the help or support of other children, they should be held accountable

- Inform the youngster with update - Regularly check in with the child on the situation

- Seek outside help if necessary -Inform the school counselling staff about any serious problems

2.Role of parents

2.Role of parents

- Listen without rushing to any conclusions or making snap judgments - Thank the youngster for sharing his or her storey with you - No matter how tough it is, show empathy and listen to his or her feelings,

-Avoid criticising the child - Ask inquiries to get as much information as possible about all persons engaged in the problem -Inform the teacher about the situation and how you plan to handle it - If you suspect your kid is in danger at any time, contact the school right away for help

\section{Conclusions}

School bullying is one of violence form that could be a major concern for pupils and a global public. The wide range of the prevalence of school bullying may be due to different methodologies and the presence of many risk factors. It is recommended to have long-term research about the student with bullying behavior. Also, prevention programs are required to increase knowledge and early detection of affected students to prevent future psychiatric disorders.

\section{Abbreviations}

POTS: Perception of Teasing Scale.; ADHD: Attention deficit hyperactivity disorder.

\section{Acknowledgements \\ None.}

\section{Authors' contributions}

GA and MS searched,collected papers and were the contributors in writing the manuscript. IS, NM and KE revised review, and manuscript. All authors read and approved the final manuscript.

\section{Funding}

This research did not receive any specific grant from funding agencies in the public, commercial, or not-for-profit sectors.

\section{Availability of data and materials}

Data sharing is not applicable to this article as no data sets were generated or analyzed during the current study. 


\section{Declarations}

Ethics approval and consent to participate

No ethical approval was obtained or required for the purposes of this review.

\section{Consent for publication}

Not applicable.

\section{Competing interests}

The authors declare no conflicts of interests.

\section{Author details}

'Department of Neurology and Psychiatry, Faculty of Medicine, Assiut University, Assiut, Egypt. ${ }^{2}$ Department of Child \& Adolescent Psychiatry, King's College London, London SE5 8AF, UK. ${ }^{3}$ Department of Neurology and Psychiatry, Al-Azhar University Hospital, Assiut, Egypt. ${ }^{4}$ Department of Psychiatry, Sohag Mental Health Hospital, Sohag, Egypt.

Received: 6 October 2021 Accepted: 14 January 2022 Published online: 05 February 2022

\section{References}

1. National Center for Educational Statistics: Student Reports of Bullying and Cyberbullying: Results from the 2015 School Crime Supplement to the National Victimization Survey. http://nces.ed.gov/pubsearch/pubsinfo. asp?pubid $=2016056.2016$

2. American Psychological Association: Bullying. (2020). Accessed Accessed on 25-8-2020 from : https://www.apa.org/topics/bullying.

3. Gladden RM, Vivolo-Kantor AM, Hamburger ME, Lumpkin CD. Bullying surveillance among youths: Uniform definitions for public health and recommended data elements, version 1.0. 2014

4. Bauman S, Del Rio A. Preservice teachers' responses to bullying scenarios: Comparing physical, verbal, and relational bullying. J Educ Psychol. 2006;98(1):219.

5. Zych I, Ortega-Ruiz R, Marín-López I. Cyberbullying: a systematic review of research, its prevalence and assessment issues in Spanish studies. Psicología Educativa. 2016;22(1):5-18.

6. Ez-Elarab HS, Sabbour SM, Gadallah MA, Asaad TA. Prevalence and risk factors of violence among elementary school children in Cairo. J Egypt Public Health Assoc. 2007;82(1-2):127-46.

7. Galal YS, Emadeldin M, Mwafy MA. Prevalence and correlates of bullying and victimization among school students in rural Egypt. J Egypt Public Health Assoc. 2019;94(1):1-12.

8. Ahmed GK, Metwaly NA, Elbeh K, Galal MS, Shaaban I. Prevalence of school bullying and its relationship with attention deficit-hyperactivity disorder and conduct disorder: a cross-section study. Egypt J Neurol Psychiatry Neurosurg.

9. Fleming $\mathrm{LC}$, Jacobsen $\mathrm{KH}$. Bullying among middle-school students in low and middle income countries. Health Promot Int. 2010;25(1):73-84.

10. Modecki KL, Minchin J, Harbaugh AG, Guerra NG, Runions KC. Bullying prevalence across contexts: a meta-analysis measuring cyber and traditional bullying. J Adolesc Med. 2014;55(5):602-11.

11. Sittichai R, Smith PK. Bullying in south-east Asian countries: A review. Aggress Violent Beh. 2015;23:22-35.

12. United Nations Educational SaCO: School violence and bullying : Global status and trends, drivers and consequences. Paris: UNESCO. 2018. https://hivhealthclearinghouse.unesco.org/library/documents/schoolviolence-and-bullying-global-status-and-trends-drivers-and-consequenc es.

13 Quiroz H, Arnette J, Stephens R. Bullying in schools: Discussion activities for school communities. California: National School Safety Center; 2006.

14. Merrill RM, Hanson CL. Risk and protective factors associated with being bullied on school property compared with cyberbullied. BMC Public Health. 2016;16(1):1-10.

15. Tsorbatzoudis H, Travlos AK, Rodafinos A. Gender and age differences in self-reported aggression of high school students. J Interpers Violence. 2013;28(8):1709-25.
16. Smith PK. Bullying: definition, types, causes, consequences and intervention. Soc Pers Psychol Compass. 2016;10(9):519-32.

17. Jan A, Husain S. Bullying in elementary schools: its causes and effects on students. J Educ Pract. 2015;6(19):43-56.

18. Cook CR, Williams KR, Guerra NG, Kim TE, Sadek S. Predictors of bullying and victimization in childhood and adolescence: A meta-analytic investigation. Sch Psychol Q. 2010;25(2):65-83.

19. Farrington $D$, Baldry A. Individual risk factors for school bullying. Journal of aggression, conflict and peace research. 2010

20. Smith PK, Madsen KC, Moody JC. What causes the age decline in reports of being bullied at school? Towards a developmental analysis of risks of being bullied. Educ Res. 1999:41(3):267-85.

21. Pellegrini AD, Long JD, Solberg D, Roseth C, Dupuis D. Bullying and social status during school transitions. In: Handbook of Bullying in Schools. Routledge; 2009. p. 209-20.

22. Jimerson SR, Swearer SM, Espelage DL. Handbook of bullying in schools: An international perspective. 2009.

23. Due P, Merlo J, Harel-Fisch Y, Damsgaard MT, Soc MS, Holstein BE, et al. Socioeconomic inequality in exposure to bullying during adolescence: A comparative, cross-sectional, multilevel study in 35 countries. Am J Public Health. 2009;99(5):907-14.

24. Unnever JD, Cornell DG. Bullying, self-control, and ADHD. J Interpers Violence. 2003;18(2):129-47.

25. Greenleaf C, Petrie TA, Martin SB. Relationship of weight-based teasing and adolescents' psychological well-being and physical health. J Sch Health. 2014;84(1):49-55.

26. Fanti KA, Kimonis ER. Bullying and victimization: the role of conduct problems and psychopathic traits. J Res Adolesc. 2012;22(4):617-31.

27. Pepler D, Craig W. Understanding and Addressing Bullying: An International Perspective PREVNet Series. Author House; 2008.

28. Reijntjes A, Vermande M, Thomaes S, Goossens F, Olthof T, Aleva L, et al. Narcissism, bullying, and social dominance in youth: a longitudinal analysis. J Abnorm Child Psychol. 2016;44(1):63-74.

29. Sentse M, Kiuru N, Veenstra R, Salmivalli C. A social network approach to the interplay between adolescents' bullying and likeability over time. J Youth Adolesc. 2014:43(9):1409-20.

30. Barboza GE, Schiamberg LB, Oehmke J, Korzeniewski SJ, Post LA, Heraux CG. Individual characteristics and the multiple contexts of adolescent bullying: an ecological perspective. J Youth Adolesc. 2009;38(1):101-21.

31. Anton-Erxleben K, Kibriya S, Zhang Y. Bullying as the main driver of low performance in schools: Evidence from Botswana, Ghana, and South Africa. 2016

32. Rose CA, Swearer SM, Espelage DL. Bullying and students with disabilities: the untold narrative. Focus Except Child. 2012:45(2):1-10.

33. Lodder GM, Scholte RH, Cillessen AH, Giletta M. Bully victimization: selection and influence within adolescent friendship networks and cliques. $J$ Youth Adolesc. 2016:45(1):132-44.

34. Bradshaw CP, Waasdorp TE, Goldweber A, Johnson SL. Bullies, gangs, drugs, and school: understanding the overlap and the role of ethnicity and urbanicity. J Youth Adolesc. 2013;42(2):220-34.

35. Brewer SL Jr. Addressing youth bullying through the whole child model Education. 2017;138(1):41-6.

36. Gaete J, Tornero B, Valenzuela D, Rojas-Barahona CA, Salmivalli C, Valen-

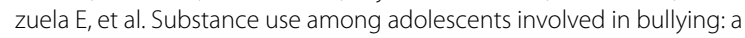
cross-sectional multilevel study. Front Psychol. 2017;8:1056.

37. Kasen S, Johnson JG, Chen H, Crawford TN. School climate and change in personality disorder symptom trajectories related to bullying: A prospective study. Bullying in North American schools. Routledge; 2010. p. 181-201.

38. Pörhölä M, Almonkari M, Kunttu K. Bullying and social anxiety experiences in university learning situations. Soc Psychol Educ. 2019;22(3):723-42.

39. Yoon J, Bauman S. Teachers: A critical but overlooked component of bullying prevention and intervention. Theory Into Practice. 2014;53(4):308-14.

40. Kochenderfer-Ladd B, Pelletier ME. Teachers' views and beliefs about bullying: Influences on classroom management strategies and students' coping with peer victimization. J Sch Psychol. 2008;46(4):431-53.

41. Bilz L. On the accuracy of German teachers' identification of pupils involved in bullying. In: 31st International Congress of Psychology, 24-29 July 2016, Yokohama, Japan. Chichester: Wiley; 2016. p. 462 
42. Doll B, Song S, Champion A, Jones K. Classroom ecologies that support or discourage bullying. Bullying NAm Schools. 2011;2:147-58.

43. Swearer SM, Espelage DL. Expanding the social-ecological framework of bullying among youth: Lessons learned from the past and directions for the future. Bullying in north American schools. Routledge; 2010. p. 23-30.

44. Swearer S, Espelage DL, Vaillancourt T, Hymmel S. What can be done about school bullying? linking research to educational practice. Educ Res. 2010;39:38-47.

45. Duncan RD. Family relationships of bullies and victims. Bullying in North American schools: Routledge; 2010. p. 211-24.

46. Mares M-L, Kretz V. Media effects on children. 2015

47. Burger C, Strohmeier D, Spröber N, Bauman S, Rigby K. How teachers respond to school bullying: An examination of self-reported intervention strategy use, moderator effects, and concurrent use of multiple strategies. Teach Teach Educ. 2015;51:191-202.

48. El-Desoky M. Bullying Behavior Scale for children and adolescents. 2016.

49. Orpinas P, Frankowski R. The Aggression Scale: a self-report measure of aggressive behavior for young adolescents. J Early Adolesc. 2001;21(1):50-67.

50. Austin S, Joseph S. Assessment of bully/victim problems in 8 to 11 yearolds. Br J Educ Psychol. 1996;66(4):447-56.

51. Bosworth K, Espelage DL, Simon TR. Factors associated with bullying behavior in middle school students. J Early Adoles. 1999;19(3):341-62.

52. Bond L, Wolfe S, Tollit M, Butler H, Patton G. A comparison of the Gatehouse Bullying Scale and the Peer Relations Questionnaire for students in secondary school. J Sch Health. 2007;77(2):75-9.

53. Schäfer M, Korn S, Smith PK, Hunter SC, Mora-Merchán JA, Singer MM, et al. Lonely in the crowd: recollections of bullying. Br J Dev Psychol. 2004;22(3):379-94.

54. Thompson JK, Cattarin J, Fowler B, Fisher E. The perception of teasing scale (POTS): a revision and extension of the physical appearance related teasing scale (PARTS). J Pers Assess. 1995;65(1):146-57.

55. Chan JH, Myron R, Crawshaw M. The efficacy of non-anonymous measures of bullying. Sch Psychol Int. 2005;26(4):443-58.

56. Wolke D, Woods S, Bloomfield L, Karstadt L. The association between direct and relational bullying and behaviour problems among primary school children. J Child Psychol Psychiatry Allied Disciplines. 2000;41(8):989-1002.

57. Espelage DL, Holt MK. Bullying and victimization during early adolescence: Peer influences and psychosocial correlates. J Emot Abus. 2001;2(2-3):123-42.

58. Gini G, Pozzoli T. Bullied children and psychosomatic problems: A metaanalysis. Pediatrics. 2013;132(4):720-9.

59. Swearer SM, Hymel S. Understanding the psychology of bullying: Moving toward a social-ecological diathesis-stress model. Am Psychol. 2015;70(4):344-53.

60. Wolke D, Lereya ST. Long-term effects of bullying. Arch Dis Child. 2015;100(9):879-85.

61. Sigurdson JF, Undheim AM, Wallander JL, Lydersen S, Sund AM. The longterm effects of being bullied or a bully in adolescence on externalizing and internalizing mental health problems in adulthood. Child Adolesc Psychiatry Ment Health. 2015;9:42.

62. Copeland WE, Wolke D, Angold A, Costello EJ. Adult psychiatric outcomes of bullying and being bullied by peers in childhood and adolescence. JAMA Psychiat. 2013;70(4):419-26.

63. Moore SE, Norman RE, Suetani S, Thomas HJ, Sly PD, Scott JG. Consequences of bullying victimization in childhood and adolescence: $A$ systematic review and meta-analysis. World J Psychiatry. 2017;7(1):60-76.

64. Gini G, Pozzoli T. Association between bullying and psychosomatic problems: a meta-analysis. Pediatrics. 2009;123(3):1059-65.

65. Klomek AB, Sourander A, Elonheimo H. Bullying by peers in childhood and effects on psychopathology, suicidality, and criminality in adulthood. Lancet Psychiatry. 2015;2(10):930-41.

66. Kumpulainen K. Psychiatric conditions associated with bullying. Int J Adolesc Med Health. 2008;20(2):121-32.

67. Glew G, Rivara F, Feudtner C. Bullying: Children hurting children. Pediatr Rev. 2000;21(6):183-90.

68. Kumpulainen K, Räsänen E, Puura K. Psychiatric disorders and the use of mental health services among children involved in bullying. Aggress Behav. 2001;27(2):102-10.
69. Coolidge FL, Segal DL, Estey AJ, Neuzil PJ. Preliminary Psychometric Properties of a Measure of Karen Horney's Theory in Children and Adolescents.

70. Oliver R, Hoover JH, Hazler R. The perceived roles of bullying in smalltown midwestern schools. J Couns Dev. 1994;72(4):416-20.

71. Ireland JL, Power CL. Attachment, emotional loneliness, and bullying behaviour: A study of adult and young offenders. Aggres Behav. 2004;30(4):298-312

72. Sourander A, Jensen P, Rönning JA, Niemelä S, Helenius H, Sillanmäki $L$, et al. What is the early adulthood outcome of boys who bully or are bullied in childhood? The Finnish "From a Boy to a Man" study. Pediatrics. 2007;120(2):397-404

73. World Health Organization. Preventing Suicide: A Global Imperative. 2014.

74. Davis SNC. The youth voice project. http://njbullying.org/documents/ YVPMarch2010.pdf. 2010.

75. Kann L, Kinchen S, Shanklin SL, Flint KH, Kawkins J, Harris WA, et al. Youth risk behavior surveillance-United States, 2013. MMWR supplements. 2014;63(4):1-168

76. The United Nations Children's Fund U: Protecting children from violence in school. https://www.unicef.org/protection/violence-against-childrenin-school. 2021.

77. MARINA M: How We Can Stand Against Bullying in Egyptian Schools. https://egyptianstreets.com/2021/09/07/how-we-can-stand-againstbullying-in-egyptian-schools/. 2021.

78. EgyptWatch: Bullying and racism rise in Egypt. https://egyptwatch.net/ 2020/09/23/bullying-and-racism-rise-in-egypt/\#: :text=Last\%20July\% 2C\%20the\%20first\%20judicial\%20ruling\%20of\%20its,Sudanese\%20chi Id\%20in\%20a\%20popular\%20neighbourhood\%20in\%20Cairo. 2020.

\section{Publisher's Note}

Springer Nature remains neutral with regard to jurisdictional claims in published maps and institutional affiliations.

\section{Submit your manuscript to a SpringerOpen ${ }^{\circ}$ journal and benefit from:}

- Convenient online submission

- Rigorous peer review

- Open access: articles freely available online

High visibility within the field

- Retaining the copyright to your article

Submit your next manuscript at springeropen.com 